\title{
Air-breathing behavior, oxygen concentrations, and ROS defense in the swimbladders of two erythrinid fish, the facultative air- breathing jeju, and the non-air-breathing traira during normoxia, hypoxia and hyperoxia
}

\author{
Bernd Pelster $^{1,2}$ (D) Chris M. Wood ${ }^{3}$ (D) Ellen Jung ${ }^{3} \cdot$ Adalberto L. Val $^{4}$ (D)
}

Received: 5 October 2017 / Revised: 11 December 2017 / Accepted: 19 December 2017 / Published online: 3 January 2018

(c) The Author(s) 2018. This article is an open access publication

\begin{abstract}
The jeju Hoplerythrinus unitaeniatus and the traira Hoplias malabaricus are two neighboring genera from the family of erythrinid fish, both possessing a two-chambered physostomous swimbladder. In the jeju the anterior section of the posterior bladder is highly vascularized, and the swimbladder is used for aerial respiration; the traira, in turn, is a water-breather that uses the swimbladder as a buoyancy organ and not for aerial oxygen uptake. Measurement of swimbladder oxygen partial pressure $\left(\mathrm{PO}_{2}\right)$ of fish kept at $26^{\circ} \mathrm{C}$ in normoxic, hyperoxic $\left(28-32 \mathrm{mg} \mathrm{O}_{2} \mathrm{~L}^{-1}\right)$ or hypoxic $\left(1-1.5 \mathrm{mg} \mathrm{O}_{2} \mathrm{~L}^{-1}\right)$ water revealed constant values in traira swimbladder. Under normoxic conditions in the jeju swimbladder $\mathrm{PO}_{2}$ was higher than in traira, and the $\mathrm{PO}_{2}$ significantly increased under hyperoxic conditions, even in the absence of air breathing. In jeju, air-breathing activity increased significantly under hypoxic conditions. Hypoxic air-breathing activity was negatively correlated to swimbladder $\mathrm{PO}_{2}$, indicating that the swimbladder was intensely used for gas exchange under these conditions. In traira, the capacity of the ROS defense system, as assessed by measurement of activities of enzymes involved in ROS degradation and total glutathione (GSH + GSSG) concentration, was elevated after $4 \mathrm{~h}$ of hyperoxic and/or hypoxic exposure, although swimbladder $\mathrm{PO}_{2}$ was not affected. In jeju, experiencing a higher variability in swimbladder $\mathrm{PO}_{2}$ due to the air-breathing activity, only a reduced responsiveness of the ROS defense system to changing environmental $\mathrm{PO}_{2}$ was detected.
\end{abstract}

Keywords Air-breathing fish $\cdot$ ROS defense $\cdot$ Swimbladder $\cdot$ Hypoxia $\cdot$ Hyperoxia

\section{Introduction}

The oxygen concentration in the Amazon Basin is known to vary greatly, depending on season and the daily cycle (Val and Almeida-Val 1995; Muusze et al. 1998; Diaz and Breitburg 2009; Welker et al. 2013). To supplement oxygen

Communicated by G. Heldmaier.

Bernd Pelster

bernd.pelster@uibk.ac.at

1 Institut für Zoologie, Leopold-Franzens-Universität Innsbruck, Technikerstr. 25, 6020 Innsbruck, Austria

2 Center for Molecular Biosciences, University Innsbruck, Innsbruck, Austria

3 Department of Zoology, University of British Columbia, Vancouver, BC V6T 1Z4, Canada

4 Instituto Nacional de Pesquisas da Amazônia, Manaus, Brazil demand during periods of aquatic hypoxia, many fish of the Amazon Basin rely on aquatic surface respiration or even use specific tissues or organs for aerial gas exchange (Val and Almeida-Val 1995). In water-breathing fish arterial $\mathrm{PO}_{2}$ typically is well below aerial $\mathrm{PO}_{2}$ (Gilmour and Perry 1994; Kristensen et al. 2010). Epithelia exposed to air in these air breathing organs therefore face much higher $\mathrm{PO}_{2}$ values than tissues of water-breathing fish. Depending on the air-breathing activity and the removal of oxygen from the engulfed air, also quite variable $\mathrm{PO}_{2}$ values may be encountered in air-breathing organs.

High oxygen concentrations and especially hyperoxic conditions result in the generation of reactive oxygen species (ROS), not only in mammals but also in fish. Exposure to hyperoxia caused oxidative stress in different tissues of goldfish (brain, liver, kidney, muscle), as evidenced by an increase in protein carbonylation, TBARS (a byproduct of lipid peroxidation) and/or lipid peroxides themselves 
(Lushchak and Bagnyukova 2006; Lushchak 2011). Lipid peroxidation appears to be one of the most rapid responses to hyperoxia and this stress signal may trigger antioxidant systems (Lushchak and Bagnyukova 2006). In the airbreathing fish Heteropneustes fossilis, $3 \mathrm{~h}$ of aerial exposure resulted in an increase in protein carbonylation, an increase in TBARS, and after $6 \mathrm{~h}, \mathrm{H}_{2} \mathrm{O}_{2}$ concentration was elevated in brain tissue (Paital 2013). In muscle tissue, TBARS and $\mathrm{H}_{2} \mathrm{O}_{2}$ were elevated after $3 \mathrm{~h}$ of exposure and protein carbonylation after $6 \mathrm{~h}$ (Paital 2014). These results support the conclusion that air-exposed epithelia in fish face oxidative stress, and this does not only affect the air-exposed epithelia, it affects the whole organism. Indeed, in a recent study on erythrinid fishes, we demonstrated that there was a higher ROS defense capacity not only in the swimbladder tissue but also in the muscle tissue, of the facultative air-breathing jeju (Hoplerythrinus unitaeniatus) relative to its non-airbreathing close relative, the traira (Hoplias malabaricus) (Pelster et al. 2016). The jeju uses its swimbladder as an air-breathing organ, whereas the traira uses the swimbladder only as a buoyancy organ. In non-ventilated gas cavities such as the traira swimbladder, inert gases such as nitrogen accumulate (Piiper 1965), so that $\mathrm{PO}_{2}$ in traira swimbladder is expected to be much lower than in the jeju swimbladder.

While the connection between hyperoxia and the generation of ROS has been unequivocal, the relation between hypoxic conditions and the formation of ROS has been debated intensively. It was originally expected that the reduction in oxygen availability would result in a concomitant decrease in ROS production because oxygen is required for the generation of ROS (Welker et al. 2013). Meanwhile, several studies have shown, however, that reduced oxygen availability (hypoxia) may also cause oxidative stress (Welker et al. 2013). In fish, hypoxia-induced oxidative stress has been detected in several species, including goldfish Carassius auratus (Lushchak et al. 2001), common carp Cyprinus carpio (Lushchak et al. 2005b), rotan Perccottus glenii (Lushchak and Bagnyukova 2007), medaka (Oryzias latipes) (Lushchak and Bagnyukova 2007; Oehlers et al. 2007), piapara (Leporinus elongatus) (Wilhelm Filho et al. 2005) and the Indian catfish Clarias batrachus (Tripathi et al. 2013).

To prevent tissue damage in situations of variable oxygen availability when there is the danger of inordinate accumulation of ROS, animals have developed a defense system for rapidly breaking down ROS (Storey 1996; Wilhelm Filho 1996). This system consists of low molecular weight antioxidants such as glutathione (GSH + GSSG), thioredoxin (Trx-( $\left.\mathrm{SH}_{2}\right) / \operatorname{Trx}-\mathrm{SS}-\mathrm{Trx}$ ), ascorbic acid (vitamin C), retinol (vitamin A) or $\alpha$-tocopherol (vitamin E). In addition, several enzymes can remove ROS, such as catalase and superoxide dismutase (SOD). SOD catalyzes the dismutation of $\mathrm{O}_{2}{ }^{-}$into $\mathrm{O}_{2}$ and $\mathrm{H}_{2} \mathrm{O}_{2}$, and catalase decomposes $\mathrm{H}_{2} \mathrm{O}_{2}$. Glutathione peroxidase (GPx) also decomposes $\mathrm{H}_{2} \mathrm{O}_{2}$ using the
GSH in its reduced form, and glutathione reductase (GR) subsequently reduces GSSG back to GSH at the expense of $\mathrm{NADPH}_{2}$ (Hermes-Lima 2004). Oxidized NADP ${ }^{+}$may then be reduced again by the activity of glucose-6-phosphate dehydrogenase and 6-phosphogluconate dehydrogenase, enzymes of the pentose phosphate shunt.

By exposing fish to variable oxygen conditions (hypoxia as well as hyperoxia), it has been shown that the ROS defense system is quite flexible. Hyperoxic exposure not only induces an increased activity of ROS-degrading enzymes (Lushchak et al. 2005a; Lushchak and Bagnyukova 2006; Lushchak 2011) but also hypoxia often results in an increase in the activity of these enzymes (Lushchak et al. 2001, 2005b; Wilhelm Filho et al. 2005; Lushchak and Bagnyukova 2007; Tripathi et al. 2013). The latter may be the response to an increase in ROS under hypoxic conditions, but it may also be a preparation of the organism for oxidative stress encountered during recovery from hypoxia, and the concept of a preparation for oxidative stress is widely accepted (Welker et al. 2013). In the present study, we, therefore, hypothesized that the ROS defense system of the two erythrinids, jeju (Hoplerythrinus unitaeniatus) and traira (Hoplias malabaricus), would also show this flexibility to changing oxygen availability. We also hypothesized that the swimbladder of the air-breathing jeju, depending on the air-breathing activity, is frequently facing changing oxygen partial pressures, while the swimbladder of the non-air-breathing traira was expected to face more or less constant low-oxygen partial pressures. Based on the results obtained, we intended to assess the possible contribution of the swimbladder to gas exchange.

\section{Materials and methods}

Experiments were performed at the Instituto Nacional de Pesquisas da Amazônia (INPA). All procedures were in compliance with Brazilian national and INPA animal care regulations.

Erythrinid fish used for this study, the jeju and the traira, were caught by INPA fishermen, brought to the INPA and kept in outdoor fish tanks, supplied with running INPA freshwater. The water was continuously aerated. In the tanks, the fish had free access to air and could, therefore, breathe air voluntarily. Fish were fed daily until the day before the experiment. Water $\mathrm{pH}$ was $6.0 \pm 0.05$, the temperature was $26 \pm 1{ }^{\circ} \mathrm{C}$.

\section{Surgical procedure in jeju}

Jeju were anaesthetized with neutralized MS222 $\left(0.1 \mathrm{~g} \mathrm{~L}^{-1}\right)$. The body wall was opened close to the lateral line below the end of the dorsal fin. A Clay-Adams PE50 catheter (Becton, 
Dickinson and Co., Franklin Lakes, NJ, USA), slightly flared at the insertion end, was inserted into the caudal end of the posterior swimbladder and anchored in place with a surgical suture and a drop of cyanoacrylate tissue glue (Vetbond ${ }^{\mathrm{TM}}$, 3M Co., Maplewood, MN, USA). The catheter was guided through the muscle tissue and the skin using a PE160 sleeve, which was anchored to the PE50 with the glue, then sutured to the body surface. After surgery, fish were transferred to 25-L plastic tanks with aerated INPA freshwater for a recovery period of at least $16 \mathrm{~h}$.

\section{Behavioral observations and in vivo measurements of swimbladder oxygen in jeju}

Jeju with a catheter inserted into the posterior swimbladder were transferred to translucent 2-L plastic tanks, filled with INPA freshwater until about $6 \mathrm{~cm}$ below the top of the tank so the fish could breathe air freely. Outside the tank, the catheter was connected to a gas-tight glass syringe so that gas samples from the posterior swimbladder could be taken without disturbing the fish.

Water was aerated using air stones (normoxia $=7-8 \mathrm{mg}$ $\mathrm{O}_{2} \mathrm{~L}^{-1}$, corresponding to a $\mathrm{PO}_{2}$ of $20 \mathrm{kPa}$ ). After an acclimation period of at least $2 \mathrm{~h}$, fish were observed for $30 \mathrm{~min}$ by counting every air-breath. Air-breaths could easily be identified because immediately after the fish left the surface, exhaled air bubbles left the opercular cavity via the operculum. Then the water $\mathrm{PO}_{2}$ was lowered to $1-1.5 \mathrm{mg} \mathrm{O} \mathrm{L}^{-1}$ (corresponding to a $\mathrm{PO}_{2}$ of $2.6-3.9 \mathrm{kPa}$ or about $17 \%$ saturation; hypoxia) by bubbling nitrogen into the tank. After the water was equilibrated to the new $\mathrm{PO}_{2}$, air-breathing activity was again monitored for 30 min by counting every air breath. At the end of this hypoxia treatment, water was aerated and the fish were allowed a recovery period of $2 \mathrm{~h}$. Following this recovery period, water was bubbled with pure oxygen to achieve hyperoxic conditions (28-32 $\mathrm{mg} \mathrm{O}_{2} \mathrm{~L}^{-1}$, corresponding to a $\mathrm{PO}_{2}$ of $73-83 \mathrm{kPa}$ or about $450 \%$ saturation). Air-breathing activity was again counted for $30 \mathrm{~min}$. Water oxygen levels were recorded with a portable oxygen electrode and meter (WTW Multi3410 meter, Weilheim, Germany) for normoxic and hypoxic conditions. Hyperoxic conditions were verified using a Clark-type oxygen electrode and the appropriate meter (Radiometer, E5047 electrode, connected to a PHM 73 m, Copenhagen, Denmark).

Swimbladder gas samples of $0.2-0.3 \mathrm{~mL}$ were taken at the end of the control period, and at the end of the hypoxic or hyperoxic incubation. After disconnecting the syringe from the catheter, the syringe was immediately sealed with parafilm and the $\mathrm{PO}_{2}$ of the gas sample was measured using a PreSens optical oxygen probe (PreSens Precision Sensing, Regensburg, Germany), inserted into a $22 \mathrm{G}$ needle. With this needle, the parafilm blocking the tip of the glass syringe containing the gas sample was penetrated and the oxygen probe advanced to measure the $\mathrm{PO}_{2}$ of the gas sample. After the measurement, the gas sample was returned to the posterior swimbladder. The probe was calibrated with air and nitrogen in the gas phase. Aerial oxygen was set to $100 \%$ $(20 \mathrm{kPa})$, and nitrogen was set to zero oxygen.

\section{Hypoxic and hyperoxic incubations in jeju and traira}

Fish were transferred to individual 30-L plastic tanks the day before the experiment. Water was aerated using air stones. The next morning, $75 \%$ of the water was siphoned out of the tank and replaced with fresh water. For hypoxic conditions, water oxygen was lowered to $1-1.5 \mathrm{mg} \mathrm{O}_{2} \mathrm{~L}^{-1}$ (corresponding to a $\mathrm{PO}_{2}$ of $2.6-3.9 \mathrm{kPa}$; hypoxia) by bubbling nitrogen into the tank. Fish were incubated under hypoxic conditions for $4 \mathrm{~h}$. Hyperoxic conditions (28-32 $\mathrm{mg} \mathrm{O}_{2}$ $\mathrm{L}^{-1}$, corresponding to a $\mathrm{PO}_{2}$ of $73-83 \mathrm{kPa}$; incubation time $4 \mathrm{~h}$ ) were achieved by bubbling oxygen. Control fish were incubated in aerated normoxic water for $4 \mathrm{~h}$. Water oxygen partial pressure was monitored using the WTW portable oxygen electrode for hypoxic and normoxic conditions, and the Radiometer Clark-type oxygen electrode for hyperoxic conditions, as above.

\section{Tissue preparation in jeju and traira}

Fish maintained for $4 \mathrm{~h}$ under normoxic, hypoxic or hyperoxic conditions were rapidly anesthetized with an overdose of neutralized tricaine methanesulfonate (MS222; $0.5 \mathrm{~g} \mathrm{~L}^{-1}$ ) and killed by a sharp blow on the head. To prevent further blood flow to the swimbladder and possible modification of swimbladder gas, fish were then immediately injected with $1 \mathrm{~mL}$ of $100 \mathrm{mM} \mathrm{KCl}$ into the caudal vein. Preliminary tests showed that this stopped the heart within $30 \mathrm{~s}$. Fish were opened laterally and a small portion of the swimbladder was carefully exposed for measurement of $\mathrm{PO}_{2}$ of the swimbladder using a PreSens oxygen probe housed in a $22 \mathrm{G}$ needle, as above. After penetrating the posterior section of the swimbladder, the probe was carefully advanced into the swimbladder lumen and the $\mathrm{PO}_{2}$ recorded. Subsequently, the oxygen tension of the anterior section of the swimbladder was recorded, using a separate penetration. The whole procedure starting with anesthesia and recording the oxygen tension of the posterior bladder took between 2 and $3 \mathrm{~min}$, and within less than 4 min recording of swimbladder oxygen tensions was completed.

After recording gas tensions, the swimbladder was quickly dissected. Connective tissue was removed and the remaining tissue was carefully rinsed with saline, cleaned and blotted dry. The anterior swimbladder tissue of jeju and traira and also the posterior part of traira swimbladder was dissected into small portions and immediately frozen 
in liquid nitrogen. For jeju, only the vascularized (anterior) section of the posterior swimbladder tissue was used for tissue preparation. Tissues were then stored in a biofreezer at $-80{ }^{\circ} \mathrm{C}$ until further analysis.

\section{Biochemical analyses}

For determination of total glutathione (GSSG + GSH) content of the frozen tissue samples, tissue extracts were prepared using 5\% metaphosphoric acid (MPA). The frozen tissues were ground to a fine powder and dissolved 1:5 w/v in 5\% MPA. Under ice cooling, the solution was homogenized using a motorized homogenizer. Extracts were centrifuged at $13,000 \mathrm{rpm}$ for $15 \mathrm{~min}$ at $4{ }^{\circ} \mathrm{C}$ and the supernatant was diluted using assay buffer of the GSSG + GSH Assay kit (STA-312; Cell Biolabs, Inc San Diego, USA). GSSG + GSH concentration was determined using the OxiSelect Total Glutathione (GSSG + GSH) Assay Kit (STA-312) Cell Biolabs, Inc San Diego, USA, following the manufacturer's instructions.

For measurement of enzyme activities, the frozen tissue samples were homogenized on ice in 1:5 w/v of ice-cold homogenization buffer $(10 \mathrm{mM}$ of TRIS/HCl, $0.1 \mathrm{mM}$ of disodium EDTA, $150 \mathrm{mM}$ of $\mathrm{NaCl}, \mathrm{pH} 7.5$ at $25^{\circ} \mathrm{C}$ ). Under ice cooling, the tissue was homogenized using a motorized homogenizer. Homogenates were centrifuged at 13,000 rpm for $15 \mathrm{~min}$ at $4{ }^{\circ} \mathrm{C}$ and appropriate dilutions of the supernatant were used for the enzyme and protein assays.

Enzyme activities were measured using a SpectraMax 384Plus microplate spectrophotometer (Molecular Devices, Sunnyvale, CA, USA) with temperature control at $25 \pm 0.1{ }^{\circ} \mathrm{C}$. Glutathione reductase (GR; EC 1.6.4.2.) and glutathione peroxidase (GPx; EC 1.11.1.9.) activities were measured using the Glutathione Reductase Assay Kit (No 703202; Cayman Chemical Company, Ann Harbor, USA), and the Glutathione Peroxidase Assay Kit (No 703102; Cayman Chemical Company, Ann Harbor, USA).

Catalase (Cat; EC 1.11.1.6.) activity was assayed using the Amplex Red Catalase Assay Kit (A22180; Molecular Probes, Eugene, USA). Superoxide dismutase (SOD; EC 1.15.1.1.) activity was measured following a procedure described by McCord and Fridovich (McCord and Fridovich 1969). Briefly, reactive oxygen species generated from xanthine in the xanthine oxidase reaction cause a reduction of cytochrome $\mathrm{c}$, which is inhibited by the presence of SOD. One unit of SOD activity is defined as the amount of enzyme (per milligram of protein) that inhibits the reduction of cytochrome c observed in the blank without SOD by $50 \%$.

Protein concentration in the homogenate was measured with Coomassie Brilliant Blue G-250 (Bradford 1976) using bovine serum albumin as a standard.

\section{Statistics}

Data are expressed as mean \pm 1 SEM with $\mathrm{N}$ giving the number of animals analyzed in each species. GSSG + GSH concentrations are given as nmol $\mathrm{g}^{-1} \mathrm{wwt}$ (wet weight), enzyme activities as $\mathrm{U} \mathrm{mg}^{-1}$ protein $\left(\mu \mathrm{mol} \mathrm{min}{ }^{-1} \mathrm{mg}^{-1}\right.$ protein) or as $\mathrm{mU} \mathrm{mg}{ }^{-1}$ protein (nmol min ${ }^{-1} \mathrm{mg}^{-1}$ protein). For statistical analysis three-way repeated measures ANOVA, followed by the Holm-Sidak Multiple Comparison procedures, was used. Fish species (jeju, traira), tissue (anterior bladder, posterior bladder) and incubation $\mathrm{PO}_{2}$ (normoxia, hypoxia, hyperoxia) were used as parameters (factors) 1, 2 and 3, and enzyme activity or GSH + GSSG concentration as variables (data). $\mathrm{PO}_{2}$ values of the anterior and posterior swimbladder of jeju and traira were analyzed using three-way ANOVA followed by the Bonferoni multiple comparison procedures. $\mathrm{PO}_{2}$ values of the anterior and posterior swimbladder of catheterized jeju were analyzed using one-way ANOVA followed by the Holm-Sidak multiple comparison test. In rare cases, the normality test or equal variance test failed using the original data. In this case the data were log transformed prior to statistical analysis. The statistical analysis was performed using SigmaPlot 12.0. Trend/regression lines describing the relation between $\mathrm{PO}_{2}$ and number of air breaths were calculated using Excel using a linear and a logarithmic fit. Significant differences between values were accepted for $p<0.05$.

\section{Results}

The mean body mass of jeju used for the experiments was $95.6 \pm 5.9 \mathrm{~g}($ mean \pm SEM), and the average fork length was $19.6 \pm 0.4 \mathrm{~cm}(N=26)$. The mean body mass of traira amounted to $344.1 \pm 21.9 \mathrm{~g}($ mean \pm SEM $)$, and the average fork length was $31.4 \pm 0.7 \mathrm{~cm}(N=22)$. For both species, body mass and fork length of the individual experimental groups were tested separately and there was no difference in body mass or fork length between control, hypoxic or hyperoxic animals.

Under normoxia, direct measurement of $\mathrm{PO}_{2}$ in the swimbladder on terminally sampled jeju, by direct penetration of the bladder with the oxygen probe, revealed a value of $7.08 \pm 2.9 \mathrm{kPa}$ in the anterior bladder, and only $2.6 \pm 0.54 \mathrm{kPa}(N=6)$ in the posterior bladder (Fig. 1a). In traira under normoxia, a $\mathrm{PO}_{2}$ of $4.36 \pm 2.24 \mathrm{kPa}$ was detected in the anterior bladder, and $2.42 \pm 0.62 \mathrm{kPa}(N=6)$ in the posterior bladder by the same technique (Fig. 1b). For both species, there was no significant difference between the two parts of the swimbladder.

In jeju, while $4 \mathrm{~h}$ of hypoxic incubation did not cause any change in anterior and posterior swimbladder $\mathrm{PO}_{2}, 4 \mathrm{~h}$ of hyperoxia resulted in a significantly elevated $\mathrm{PO}_{2}$ in the 

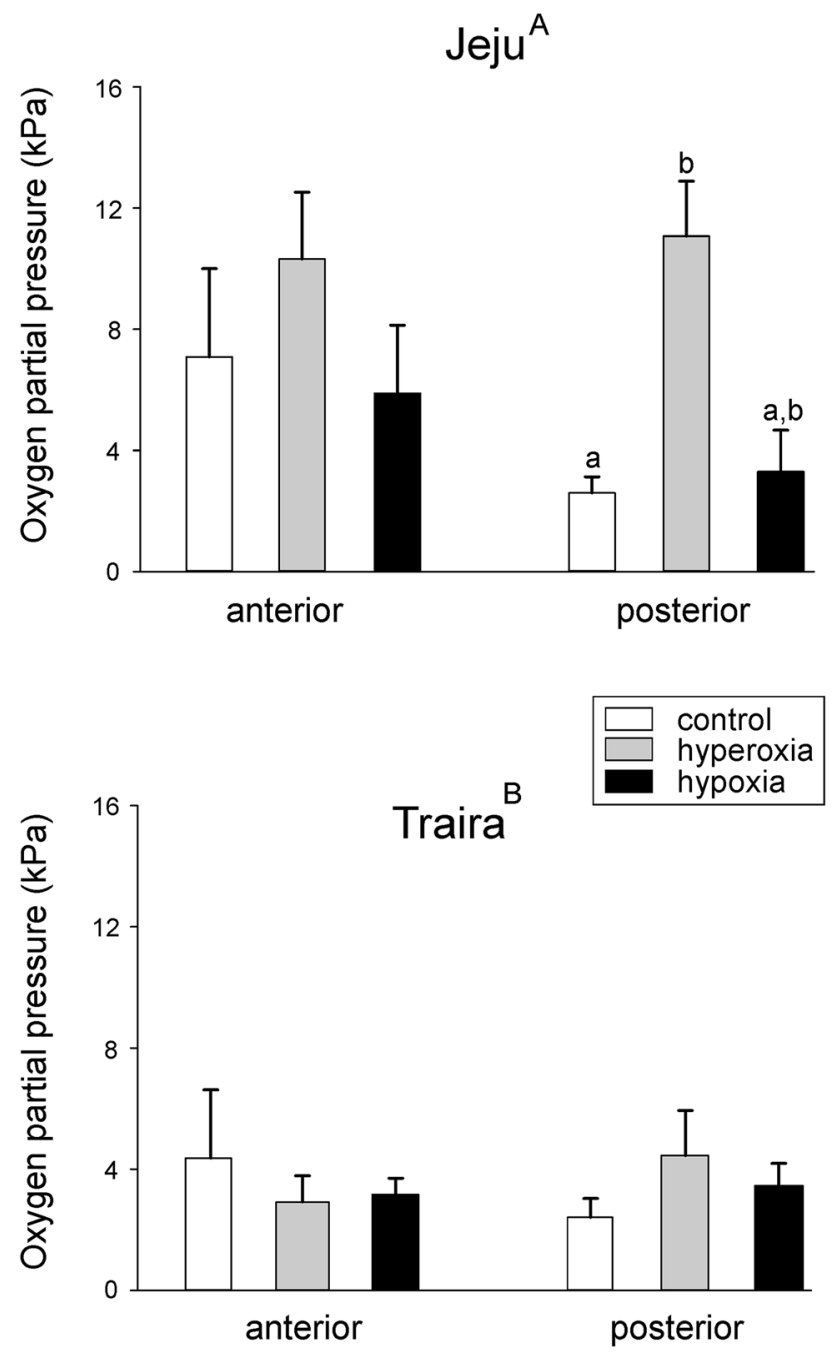

Fig. 1 Oxygen content in kPA measured by direct puncture in the anterior and posterior swimbladder of jeju (a) and traira (b) under normoxic, hypoxic and hyperoxic conditions. Different capital letters denote significant differences between species, small letters denote significant differences within a species $(p<0.05)$, bars without letters are not significantly different; $N$ is given in brackets below the columns. There was a significant overall difference between the two species

posterior bladder with $11.08 \pm 1.8 \mathrm{kPa}\left(N=5\right.$; Fig. 1a). $\mathrm{PO}_{2}$ in the anterior bladder was also elevated to approximately the same value, but the difference was not yet significant.

Visual observation of the swimming activity of traira revealed almost no surfacing activity under any of the experimental treatments. Fish were quiet on the bottom of the tank, and even ventilatory activity was hardly detectable under hypoxic conditions.

In traira neither $4 \mathrm{~h}$ of hypoxia $\left(1-1.5 \mathrm{mg} \mathrm{O}_{2} \mathrm{~L}^{-1}\right)$ nor $4 \mathrm{~h}$ of hyperoxia (28-32 $\mathrm{mg} \mathrm{O}_{2} \mathrm{~L}^{-1}$ ) caused any significant change in the $\mathrm{PO}_{2}$ of the anterior and posterior swimbladder (Fig. 1b). A comparison of swimbladder $\mathrm{PO}_{2}$ between the

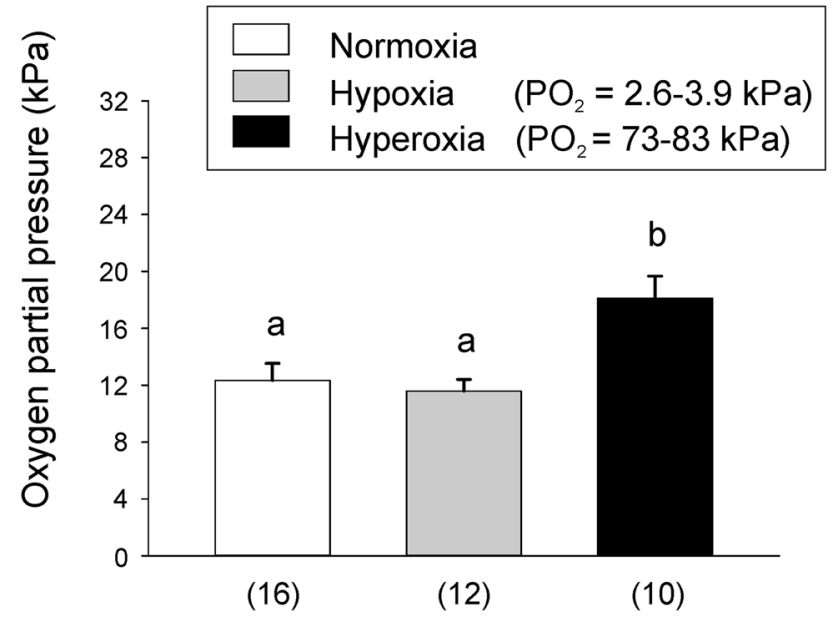

Fig. 2 Oxygen content in $\mathrm{kPa}$ measured via a catheter in the posterior swimbladder of jeju under normoxic, hypoxic and hyperoxic conditions. Different small letters denote significant differences between treatments $(p<0.05) ; N$ is given in brackets below the columns

two species revealed significantly higher levels of oxygen in jeju under both hyperoxic and hypoxic conditions (Fig. 1).

Oxygen partial pressure in the posterior bladder of jeju measured on live, freely swimming animals via a catheter chronically inserted at the caudal end of the bladder revealed significantly higher $\mathrm{PO}_{2}$ values (Fig. 2) as compared to the values obtained by puncturing the swimbladder wall and using the optical fiber (Fig. 1a). Under control conditions, the oxygen partial pressure amounted to $12.34 \pm 1.2 \mathrm{kPa}(N=16)$. A similar value was recorded after $30 \mathrm{~min}$ of hypoxia, but after $30 \mathrm{~min}$ of hyperoxia $\mathrm{PO}_{2}$ was significantly elevated to $18.1 \pm 1.56 \mathrm{kPa}(N=10$; Fig. 2). This is similar to the trend seen in the terminally sampled jeju after $4 \mathrm{~h}$ of incubation under hyperoxia (Fig. 1a), where the $\mathrm{PO}_{2}$ was also elevated as compared to normoxia. As also observed in the animals incubated for $4 \mathrm{~h}$ under hypoxic or hyperoxic conditions, hypoxia stimulated air-breathing activity, but under hyperoxic conditions no air-breathing activity was observed.

In Fig. 3a, the oxygen partial pressure of the posterior swimbladder of jeju under normoxia, as sampled by catheter in freely swimming animals, was plotted against the number of air-breaths taken in the preceding $30 \mathrm{~min}$. The data showed a remarkable variability, but the overall relationship appeared to be hyperbolic and was well described by the equation:

$$
\begin{gathered}
f=0.5699 \ln (x)+11.764\left(R^{2}=0.3642 ; f=\mathrm{PO}_{2}\right. \\
\text { of the bladder; } x=\text { number of breaths taken }) .
\end{gathered}
$$



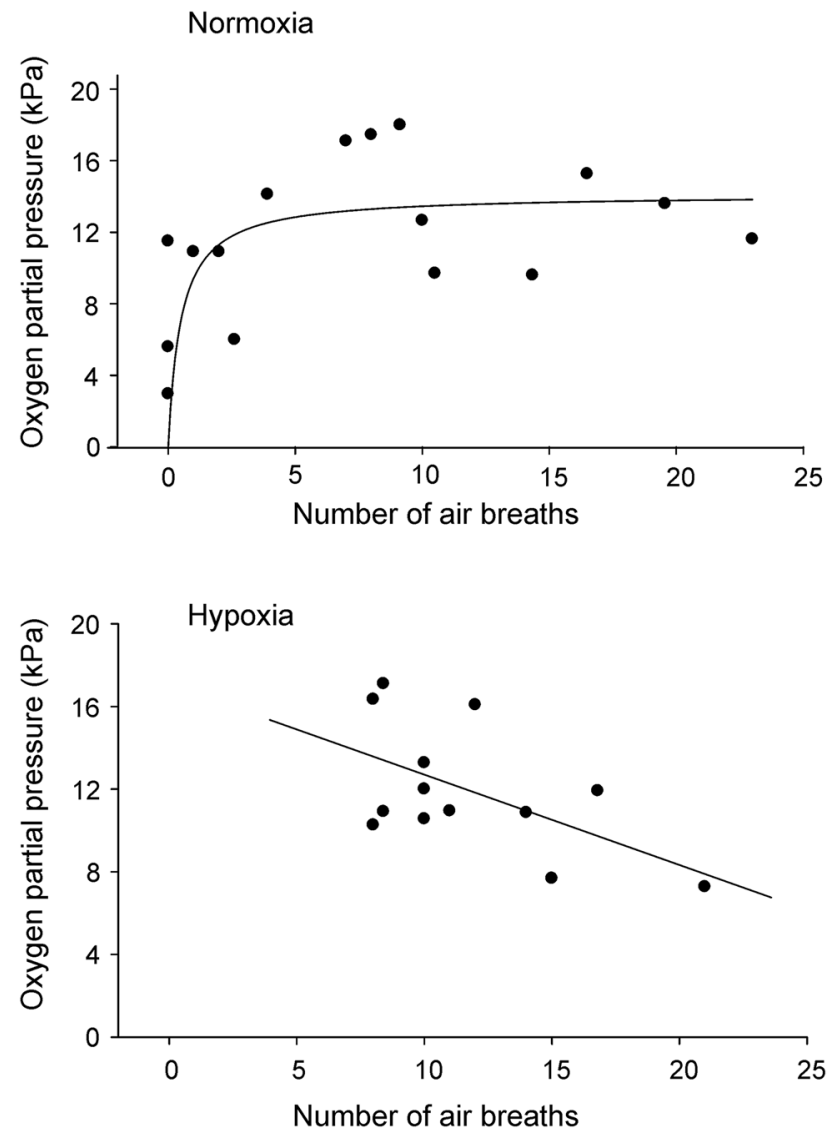

Fig. 3 Oxygen content in $\mathrm{kPa}$ measured via a catheter in the posterior swimbladder of jeju in relation to the number of breaths taken within an observation period of $30 \mathrm{~min}$ in $\mathbf{a}$ normoxic and $\mathbf{b}$ hypoxic jeju. Under hyperoxic conditions, no air-breathing activity was observed

Thus, $\mathrm{PO}_{2}$ initially increased with increasing air-breathing activity and the lowest $\mathrm{PO}_{2}$ was detected in fish that did not breathe air during the observation period. Between 5 and 25 breaths per $30 \mathrm{~min}$, however, almost no further increase in the $\mathrm{PO}_{2}$ was detectable.

Under hypoxic conditions, the scatter of the data was reduced, and the $\mathrm{PO}_{2}$ of the bladder decreased in a linear fashion with increasing number of breaths taken (Fig. 3b), as described by the equation:

$f=-0.4374 x+17.072\left(R^{2}=0.3173 ; f=\mathrm{PO}_{2}\right.$

of the bladder; $x=$ number of breaths taken).

The number of breaths taken under hypoxic conditions $(11.7 \pm 1.1$ breaths $/ 30 \mathrm{~min} ; N=13)$ was significantly higher than under normoxic conditions $(7.9 \pm 1.8$ breaths/30 $\min ; N=16$ ).

As a next step, we measured the activity of ROSdegrading enzymes in anterior and posterior swimbladder tissue of both species following incubation under normoxic control conditions, after $4 \mathrm{~h}$ of hypoxia and after
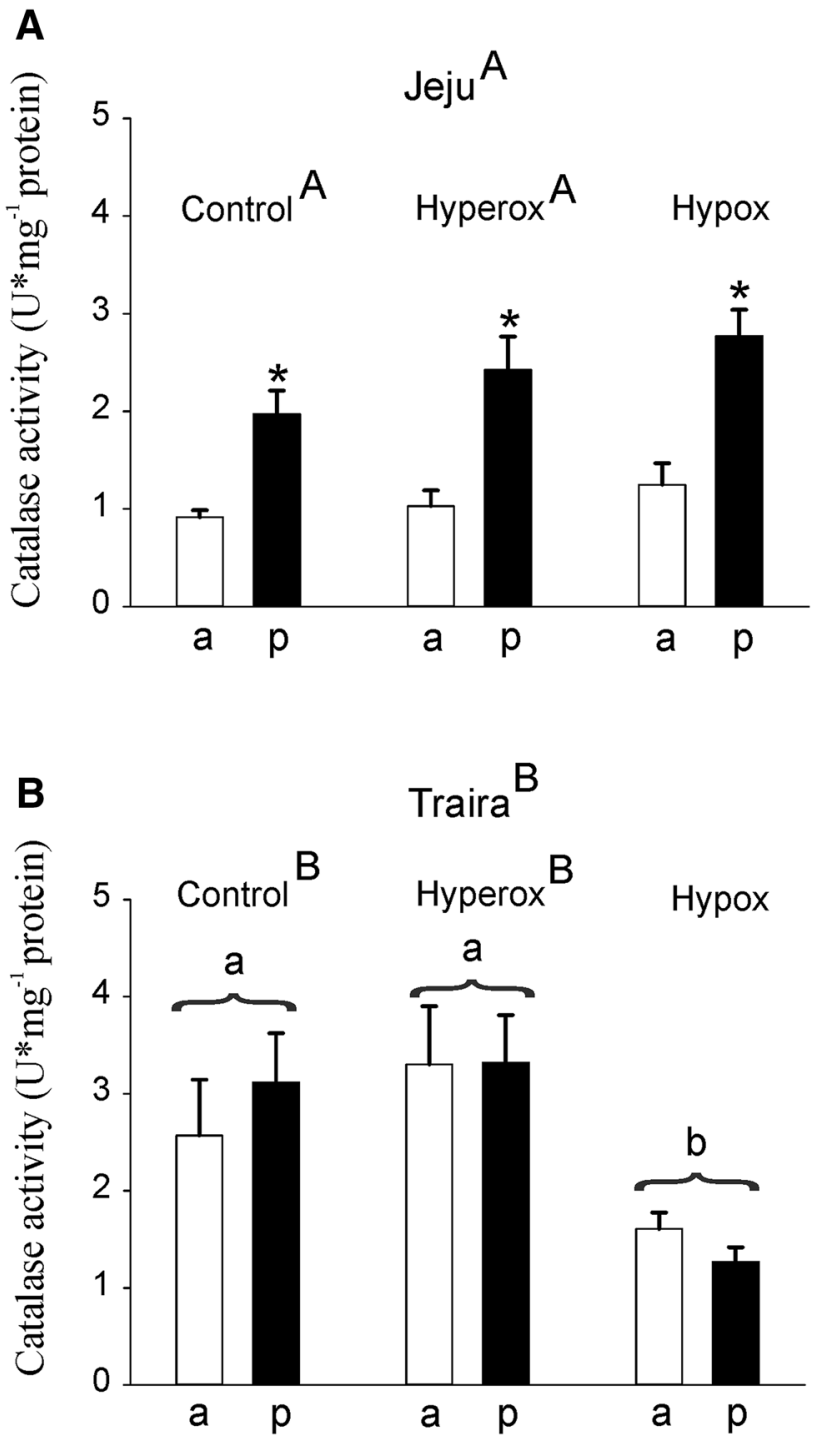

Fig. 4 Catalase activity in $\mathrm{U} \mathrm{mg}^{-1}$ protein in anterior (a) and posterior (p) swimbladder tissue of jeju (a) and traira (b) under normoxic, hyperoxic and hypoxic conditions. Asterisks mark significant differences $(p<0.05)$ between posterior and anterior values within the same species and treatment. Capital letters denote significant differences between the two species, different small letters denote significant differences between treatments within a species, bars without letters are not significantly different. There was also a significant overall difference between the two species. Jeju: control, $N=6$, hyperoxia, $N=9$, hypoxia, $N=8$; traira: control, $N=15$, hyperoxia, $\mathrm{N}=9$, hypoxia, $N=9$

$4 \mathrm{~h}$ of hyperoxia. In jeju, catalase activity in the posterior section of the swimbladder was significantly higher than in the anterior section under all three conditions tested, but there was no significant difference between normoxic, hypoxic- or hyperoxic-incubated fish (Fig. 4a). In traira, no difference was detected between the anterior and the posterior part of the swimbladder, but following $4 \mathrm{~h}$ of hypoxia-catalase activity was significantly lower by about 

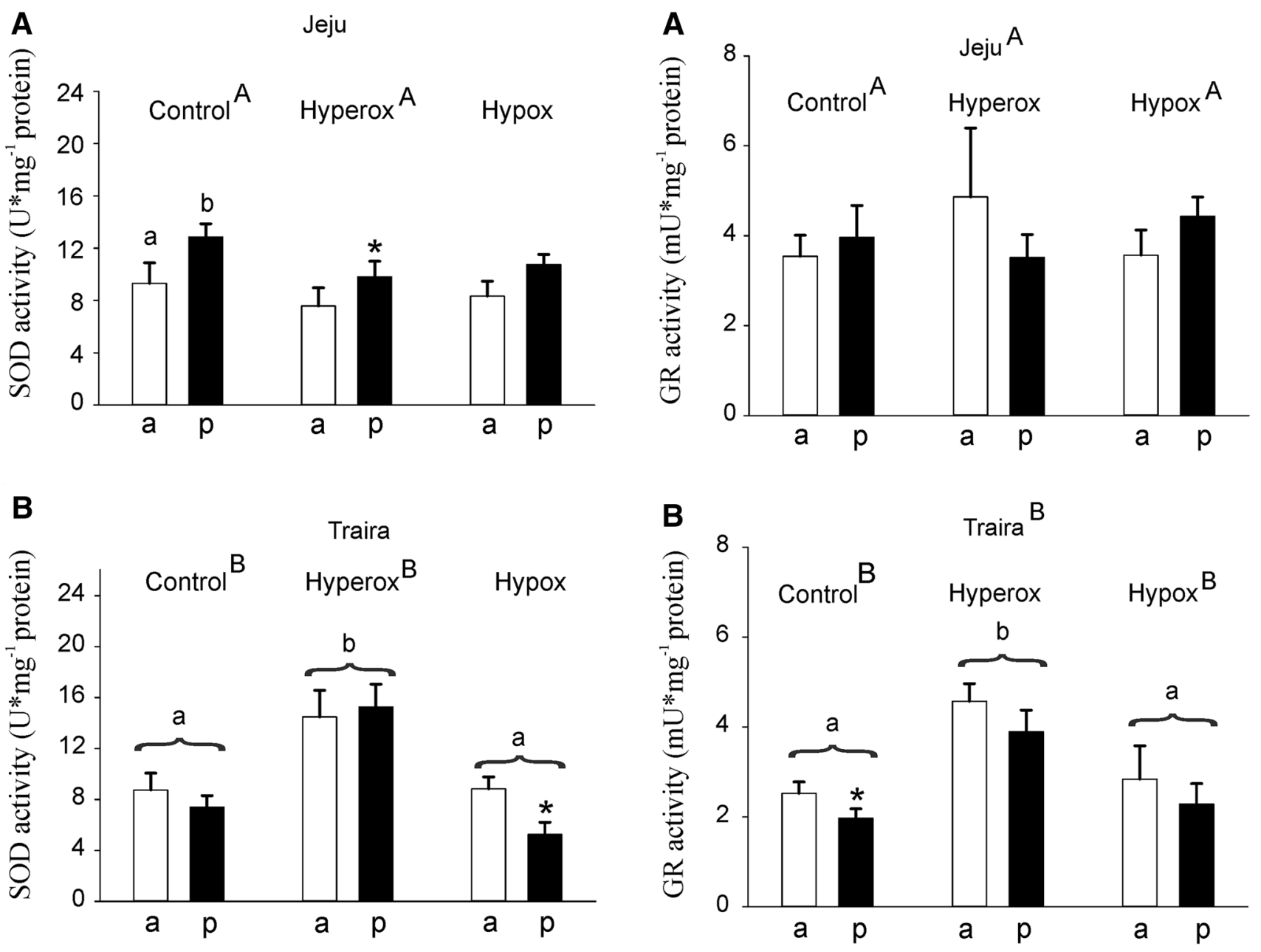

Fig. 5 Superoxide dismutase (SOD) activity in $\mathrm{U} \mathrm{mg}^{-1}$ protein in anterior (a) and posterior (p) swimbladder tissue of jeju (a) and traira (b) under normoxic, hyperoxic and hypoxic conditions. Asterisks mark significant differences $(p<0.05)$ between posterior and anterior values within the same species and treatment. Capital letters denote significant differences between the two species, different small letters denote significant differences between treatments within a species, bars without letters are not significantly different. Jeju: control, $N=11$, hyperoxia, $N=8$, hypoxia, $N=8$; traira: control, $N=14$, hyperoxia, $N=9$, hypoxia, $N=9$

$50 \%$ in both parts of the swimbladder as compared to normoxic- or hyperoxic-incubated fish (Fig. 4b). The overall comparison revealed significant differences between the two species, with specific significant differences in normoxia and hyperoxia, but not in hypoxia. Catalase activity in the posterior section of traira was significantly different from the activity measured in the posterior section of jeju.

Superoxide dismutase activity measured in jeju swimbladder tissue was similar in both sections of the swimbladder under normoxic and hypoxic conditions, but under hyperoxia SOD activity in the posterior bladder was higher than in the anterior bladder (Fig. 5a). In jeju, overall no differences could be detected in response to hypoxic or

Fig. 6 Glutathione reductase (GR) activity in $\mathrm{mU} \mathrm{mg}^{-1}$ protein in anterior (a) and posterior (p) swimbladder tissue of jeju (a) and traira (b) under normoxic, hyperoxic and hypoxic conditions. Asterisks mark significant differences $(p<0.05)$ between posterior and anterior values within the same species and treatment. Capital letters denote significant differences between the two species, different small letters denote significant differences between treatments within a species, bars without letters are not significantly different. There was also a significant overall difference between the two species. Jeju: control, $N=6$, hyperoxia, $N=8$, hypoxia, $N=8$; traira: control, $N=14$, hyperoxia, $N=9$, hypoxia, $N=8$

hyperoxic incubation (Fig. 5a). In traira, however, hyperoxic conditions caused a 1.6- to two-fold increase in SOD activity in the anterior and posterior swimbladder, respectively, and this was significantly different from control values as well as from hypoxic values (Fig. 5b). Under hypoxic conditions, SOD activity in the posterior bladder was significantly lower than in the anterior bladder. The comparison between the two species showed that under normoxic control conditions, SOD activity in jeju was significantly higher than in traira. However, under hyperoxic conditions, SOD activity was significantly higher in traira, as compared to jeju. 
Measurement of GR activity in jeju swimbladder revealed similar activity in both sections of the swimbladder, and no differences could be detected in response to hypoxic or hyperoxic incubation (Fig. 6a). In traira anterior and posterior swimbladder tissue, GR activity was also quite similar, but again, following hyperoxic incubation, the activity in both sections of traira swimbladder was significantly higher than under normoxia or following hypoxic incubation (Fig. 6b). In hyperoxia, GR activity was as almost twice as high as in normoxia. The comparison of jeju and traira showed overall significant difference between the two species. Specifically, there was significantly higher GR activity
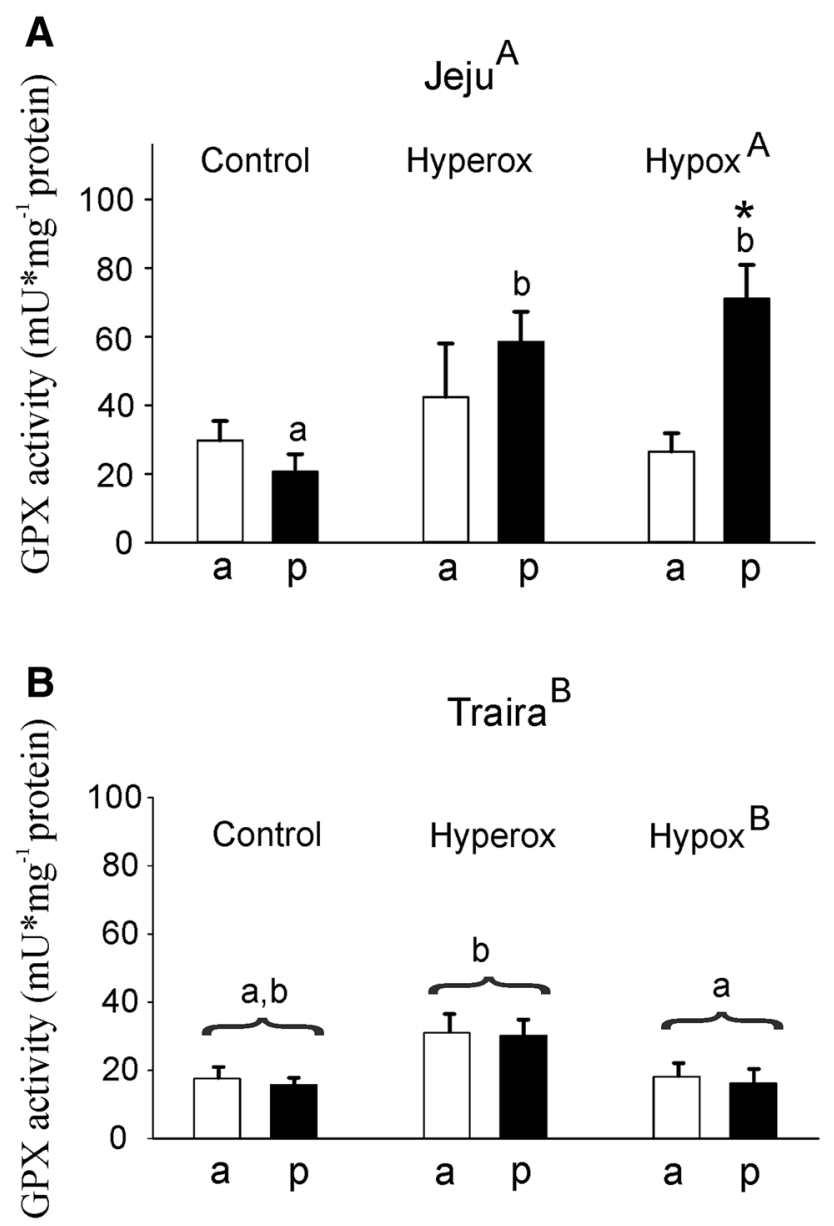

Fig. 7 Glutathione peroxidase activity in $\mathrm{mU} \mathrm{mg}^{-1}$ protein in anterior (a) and posterior (p) swimbladder tissue of jeju (a) and traira (b) under normoxic, hyperoxic and hypoxic conditions. Note the, different scales in panels $\mathbf{a}$ and $\mathbf{b}$. Asterisks mark significant differences $(p<0.05)$ between posterior and anterior values within the same species and treatment. Capital letters denote significant differences between the two species, different small letters denote significant differences between treatments within a species, bars without letters are not significantly different. There was also a significant overall difference between the two species. Jeju: control, $N=10$, hyperoxia, $N=9$, hypoxia, $N=5$; traira: control, $N=11$, hyperoxia, $N=9$, hypoxia, $N=6$ in jeju swimbladder tissue under normoxic conditions and under hypoxia, but no difference was detected under hyperoxic conditions.

Under normoxia, GPx activity was similar in the anterior and posterior section of jeju swimbladder (Fig. 7a). Hypoxic as well as hyperoxic incubation resulted in a significant enhancement of GPx activity in the posterior part of jeju swimbladder. Glutathione peroxidase activity increased 2.8fold under hyperoxic conditions and 3.4-fold under hypoxic conditions. In traira, GPx activities in the anterior and posterior section of the swimbladder were always similar to

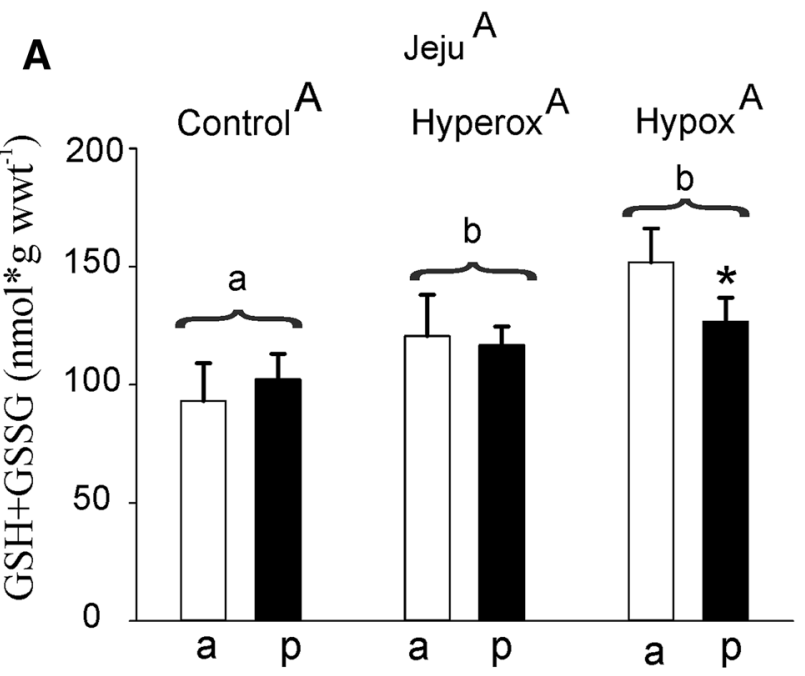

B

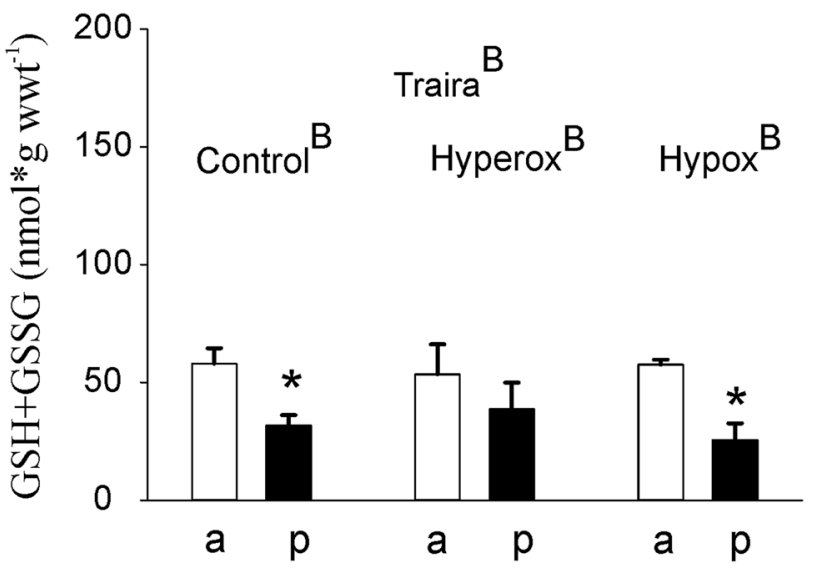

Fig. 8 Total GSSG + GSH concentration in anterior (a) and posterior (p) swimbladder tissue of jeju (a) and traira (b) under normoxic, hyperoxic and hypoxic conditions. Asterisks mark significant differences $(p<0.05)$ between posterior and anterior values within the same species and treatment. Capital letters denote significant differences between the two species, different small letters denote significant differences between treatments within a species, bars without letters are not significantly different. There was also a significant overall difference between the two species. Jeju: control, $N=6$, hyperoxia, $N=7$, hypoxia, $N=8$; traira: control, $N=6$, hyperoxia, $N=3$, hypoxia, $N=6$ 
each other, but varied according to the treatment (Fig. 7b). Under hyperoxia, GPx activity was significantly elevated as compared to hypoxia, but it was not different from the activity measured under control conditions. Overall, GPx activity was significantly higher in jeju as compared to traira, though a specific significant difference was seen only in the hypoxia treatment.

Measurement of total glutathione concentration (GSH + GSSG) again resulted in similar concentrations in the anterior and posterior section of jeju swimbladder. Comparing thevalues obtained under normoxic, hyperoxic and hypoxic conditions, however, showed a significant elevation of total glutathione concentration under hypoxic as well as under hyperoxic conditions (Fig. 8a). In traira, similar glutathione concentrations were detected under all conditions in both sections of the swimbladder. In the anterior section, the concentration always appeared to be higher, and this difference was significant for control and for hypoxic fish. Comparing the jeju with traira revealed significantly higher concentrations of total glutathione in jeju under all conditions.

\section{Discussion}

\section{Critique of methods}

Swimbladder puncture with a $22 \mathrm{G}$ needle and a fiber optic system has been used to measure oxygen content in the anterior and posterior swimbladder in quickly sacrificed animals, and chronic catheterization by inserting PE50 tubing into the caudal end of the posterior bladder in freely swimming animals. The results obtained with the catheter were significantly higher and consistent with values reported by Kramer (Kramer 1978), who collected gas by puncturing the posterior tip of the bladder and collecting gas in a water-filled funnel, and by Farrell and Randall (Farrell and Randall 1978), who cannulated the posterior bladder similar to our procedure. Comparing the changes of jeju posterior bladder oxygen content under normoxic, hypoxic and hyperoxic conditions, both procedures gave similar results qualitatively. Incubation under hypoxic conditions did not change posterior bladder oxygen content, but under hyperoxia, oxygen content increased. Both procedures appeared to have intrinsic limitations. Using the direct puncture method, the fish had to be anesthetized, and the swimbladder had to be exposed by dissection before the swimbladder wall could be penetrated with the $22 \mathrm{G}$ needle. Although the whole procedure was completed within 2 or 3 min, oxygen could have been removed from the bladder during this time and not replaced, resulting in lower oxygen values. In a previous study, we measured an oxygen uptake of $5.6 \pm 0.6 \mu \mathrm{mol} \mathrm{g}{ }^{-1}$ $\mathrm{h}^{-1}$ for jeju at a temperature of $29-32{ }^{\circ} \mathrm{C}$ (Wood et al. 2016).
Therefore, a $100 \mathrm{~g}$ of jeju would consume about $19 \mu \mathrm{mol}$ of oxygen within $2 \mathrm{~min}$. A $100 \mathrm{~g}$ of jeju would have a swimbladder volume of about $5 \mathrm{~mL}$ (Kramer 1978). Assuming an oxygen content of $60 \%(12 \mathrm{kPa}$ ) of aerial oxygen (measured in the catheter experiments), this would give an oxygen content of about $0.6 \mathrm{~mL}$, equivalent to $26 \mu \mathrm{mol}$ at STPD. Accordingly, given the time needed for anaesthesia and the further up to $30 \mathrm{~s}$ for the time needed for the injection of $\mathrm{KCl}$ to stop the heart (1.5-2 min total), the continuation of blood flow could indeed have appreciably reduced the oxygen content of the posterior swimbladder.

A problem of the catheter in turn is the tightness, and a tiny leak in the gas phase or diffusion through the PE tubing may have caused an increase in the oxygen content. The swimbladder typically contains some moisture to avoid desiccation of the epithelia, which sometimes hinders the collection of a clean gas sample. The dead space of the catheter may be equilibrated with a mixture of atmospheric and swimbladder gas, which also may result in elevated gas contents. Thus, while the direct penetration method may result in an underestimation of swimbladder oxygen content, the catheter may result in an overestimation. We, therefore, assume the real value to be in between these two results. Convincingly, however, both measurements consistently showed that jeju-posterior swimbladder oxygen content was not modified under hypoxic conditions, but it significantly increased under hyperoxic conditions.

\section{Swimbladder function under hypoxia and hyperoxia}

As expected, the swimbladder of the jeju had a significantly higher oxygen content than the swimbladder of traira. Gases are resorbed from non-ventilated cavities according to their physical solubility, resulting in an accumulation of the less soluble gases (Piiper et al. 1962; Piiper 1965). The swimbladder of traira is used as a buoyancy structure and hardly ventilated (Rantin et al. 1992; Val and Almeida-Val 1995; Glass and Rantin 2009; Pelster et al. 2016), therefore, the less soluble nitrogen should accumulate in this bladder. The jeju swimbladder, in turn, is frequently ventilated, and the inhaled gas initially enters the anterior section of the swimbladder (Randall et al. 1981). The posterior part of the jeju swimbladder is filled from the anterior part. It is highly vascularized and used as a gas exchange organ, and we measured a lower $\mathrm{PO}_{2}$ in posterior bladder as compared to the anterior part, although this difference was not yet significant.

Under normoxic conditions a large scatter in the oxygen content of the swimbladder was observed, which in part was attributable to the time difference between the last breath and sampling of swimbladder gas. In line with the results obtained for traira, the lowest oxygen content in jeju under normoxia was detected in swimbladders that were hardly ventilated. Between 5 and 25 breaths per $30 \mathrm{~min}$, however, 
oxygen content was quite variable and no clear correlation with the number of breaths taken was detectable. In addition to ventilation the intensity with which the bladder was used as an oxygen resource must have an influence, and removal of oxygen from the bladder is dependent on blood flow. In an intensely ventilated swimbladder with frequent gas exchange between the anterior and the posterior bladder, the differences in oxygen content between the two parts is expected to become smaller.

Under hypoxic conditions, ventilatory activity of the jeju increased, as reported also in previous studies (Kramer 1978; Stevens and Holeton 1978; Oliveira et al. 2004; Perry et al. 2004; Juca-Chagas 2004; Pelster et al. 2016), but the oxygen content did not increase. Indeed, a negative correlation between posterior bladder oxygen content and breathing frequency was observed. Testing the $\mathrm{PO}_{2}$ in the gas space above the hypoxic water revealed that in this set up, $\mathrm{PO}_{2}$ in the gas space may drop to $15-20 \%$ below aerial $\mathrm{PO}_{2}$ (i.e. to $16-17 \mathrm{kPa}$ ). Thus, air-breathing jeju would pick up slightly hypoxic air, but nevertheless the $\mathrm{PO}_{2}$ of this air was much higher than water $\mathrm{PO}_{2}$ with a value of only $2.6-3.9 \mathrm{kPa}$. The constant $\mathrm{PO}_{2}$ in the swimbladder, therefore, suggests that the intensely ventilated swimbladder is indeed used to supply oxygen to other tissues.

In traira under hyperoxic conditions, swimbladder oxygen content was not different from control or hypoxia-incubated animals, supporting the notion that the swimbladder is not used for gas exchange and not intensely perfused. Accordingly, changes in arterial $\mathrm{PO}_{2}$ caused by changing water $\mathrm{PO}_{2}$ will only in the long run influence swimbladder $\mathrm{PO}_{2}$. In the jeju, however, oxygen content of the posterior bladder increased significantly, as observed in both directly punctured swimbladders as well as in chronically catheterized swimbladders. No air-breathing was observed under hyperoxia in our experiments, therefore, the oxygen must have been taken up via the gills and transferred to other organs, including the posterior swimbladder. The posterior bladder has a rich vascularization and thus blood supply, whereas the anterior swimbladder is poorly vascularized. This together with the higher $\mathrm{PO}_{2}$ value recorded in the anterior bladder under normoxic conditions explain why the oxygen content in the anterior bladder was not yet significantly elevated under hyperoxic conditions.

In contrast to our previous study, where air breathing continued during hyperoxia (Pelster et al. 2016), in the present study, no air-breathing activity was observed in jeju under hyperoxic conditions. A significant reduction in air-breathing frequency under hyperoxic conditions has also been reported by Farrell and Randall (Farrell and Randall 1978). The most likely explanation for this difference appears to be the temperature. Our previous study has been performed on board a ship with temperatures of $30-35^{\circ} \mathrm{C}$ (Pelster et al. 2016), while the study of Farrell and Randall and this study have been performed at temperatures between 25 and $28^{\circ} \mathrm{C}$. The higher temperature significantly stimulates metabolic activity and oxygen requirements, but the solubility of oxygen in water decreases with temperature, impairing aquatic oxygen uptake via the gills. It is, therefore, conceivable that at high temperatures jeju resort to aerial respiration even under hyperoxic conditions to supplement oxygen uptake.

Interestingly, under severe hypoxia in traira, almost no activity was detectable, and even ventilatory activity was often hard to detect. This again contrasts with our previous study performed at a higher temperature, where traira started to perform aquatic surface respiration during severe hypoxia (Pelster et al. 2016). The present observations suggest that at $26 \pm 1{ }^{\circ} \mathrm{C}$, traira adopted a severe depression of metabolic activity to withstand the hypoxic period. Occasionally, this behavior was also seen in jeju, suggesting that the jeju has two options to survive under hypoxia, either resorting to intensive air breathing, or reducing activity and referring to metabolic depression, as does the traira.

\section{Flexibility of the ROS defense system}

The comparison of the ROS defense capacity of the jeju and the traira confirmed our previous study revealing a better ROS defense capacity in the facultative air-breathing jeju (Pelster et al. 2016), although the differences were not as clear as in the previous study. In the present study, catalase activity was even slightly higher in the traira as compared to jeju. Nevertheless, SOD and GR activity and also the concentration of GSH + GSSG were higher in jeju under control conditions. In addition, GR and GPx activity and $\mathrm{GSH}+\mathrm{GSSG}$ concentration overall were higher in jeju as compared to traira. This confirms our previous observation that the glutathione-based ROS defense system appears more important in jeju than immediate ROS breakdown by SOD (Pelster et al. 2016). The differences in the responses in comparison to our previous study most likely appear to be attributable to the lower temperature used for the present experiments. ROS formation is temperature dependent and increases with higher temperatures. Therefore, the variable oxygen tensions encountered with an enhanced air-breathing activity may stimulate the expression of a well-organized ROS defense system in the jeju, especially at higher temperature.

Considering the flexibility of the ROS defense system, our results revealed that $4 \mathrm{~h}$ of hypoxia or hyperoxia were sufficient to induce changes in some of the ROS-degrading enzymes. The responsiveness observed in traira by far exceeded the responsiveness detected in jeju swimbladder tissue. While in the jeju an elevation of activity was only observed for GPx under hyperoxic and hypoxic conditions, in traira, in turn, activities of SOD, GR and GPx were increased during hyperoxia, but catalase was reduced under 
hypoxia. This was surprising because our data demonstrated that the traira swimbladder plays no role in gas exchange, and the oxygen content was constant under all experimental conditions tested. Changing oxygen availability is detected by oxygen receptors located in the gills, and transmitted to the central nervous system (Lopes et al. 2010; Zachar and Jonz 2012; Milsom 2012). From there, the stimulus to modify the ROS defense capacity must reach various organs in the whole body; conceivably, the signal could be altered blood $\mathrm{O}_{2}$ or ROS levels, and/or other blood-borne or neural pathways. Previous studies have demonstrated that a modification of the ROS defense system is not only detectable in the gills but also in muscle tissue or in the liver, organs not in direct contact with the environmental water (see Introduction). Thus, the signaling cascade also included the swimbladder in traira.

For the jeju variable oxygen content in the bladder and thus in blood are frequently expected, depending on the air-breathing activity, and we indeed observed a significant scatter in the oxygen content of the swimbladder under normoxic conditions. Accordingly, the ROS defense system is probably pre-adjusted to variable oxygen concentrations. This may explain why in our experiments we did not observe a marked response in the ROS-detoxifying systems of swimbladders in animals exposed to either hypoxia or hyperoxia; only GPx activity was elevated in hyperoxic animals. In line with the increase in GPx activity during hyperoxia, total glutathione concentration was elevated in hyperoxia.

While our data clearly show responses of the ROS defense system to changing oxygen concentration in the swimbladder, experimental deflation of the swimbladder of Opsanus tau with subsequent increase in swimbladder oxygen content did not result in a change in enzyme activities of the ROS defense system (Morris and Albright 1984). In the European eel, however, the process of silvering, which is the preparation for the deep seawater spawning migration, is connected to a significant improvement of the ROS defense system (Schneebauer et al. 2016). Very probably, this is because much higher oxygen partial pressures are expected to occur in the swimbladder during exposure to elevated hydrostatic pressure during spawning migration than during freshwater residence (Pelster 2015). The response of the ROS defense system to changing oxygen availability appears to be quite variable and species specific. Juvenile Oncorhynchus mykiss exposed for $4 \mathrm{~h}$ to hyperoxic conditions $\left(>40 \mathrm{mg} \mathrm{O}_{2} \mathrm{~L}^{-1}\right.$ ) show an elevated catalase activity in gills and liver $24 \mathrm{~h}$ after the exposure, but not at 1 to $12 \mathrm{~h}$. SOD, total GPx and GR activity, however, were not affected (Ritola et al. 2002a). A very rapid response was observed in red blood cells, which showed an increase in SOD and catalase activity after only $5 \mathrm{~min}$ of exposure to hyperoxia (Ritola et al. 2002b). In liver of Atlantic salmon, 140-150\% oxygen saturation for several weeks increased SOD and catalase activities (Lygren et al.
2000) but in goldfish, most enzyme activities tested were not changed during hyperoxic exposure of $12 \mathrm{~h}$ (Lushchak et al. 2005a).

Goldfish exposed to anoxic conditions increased catalase activity in liver, GPx and G6PDH activity in brain (Lushchak et al. 2001) and hypoxia increased SOD activity in liver, brain and gills in common carp (Vig and Nemcsok 1989), and catalase and GPx activity in brain (Lushchak et al. 2005b). Analysis of the hypoxia response of epaulette shark, threespine stickleback and rainbow trout combined with a literature survey looking at 13 species of fish and one shark revealed that fish in general do not show an increase in antioxidant defense response under hypoxia, and if a response is seen, it is not related to the hypoxia tolerance of the species (Leveelahti et al. 2014). Following reoxygenation after a hypoxic episode, often an enhancement of the ROS defense capacity is observed, which is discussed as a preparation for the oxidative stress encountered during recovery from hypoxia (Hermes-Lima et al. 1998; Lushchak and Bagnyukova 2006; Welker et al. 2013).

The present study revealed significant differences in physiology and performance of the swimbladder of two erythrinid fish. The use of the swimbladder as an air-breathing organ in the jeju results in highly variable $\mathrm{PO}_{2}$ values in the swimbladder, depending on the frequency of breathing air. Swimbladder $\mathrm{PO}_{2}$ also appeared to be related to blood flow to the swimbladder, as suggested by the rapid increase in $\mathrm{PO}_{2}$ (within $30 \mathrm{~min}$ ) under hyperoxic conditions when no air breaths were taken, and the high variability of bladder $\mathrm{PO}_{2}$ at a similar number of breaths taken under normoxic conditions. The high variability of swimbladder $\mathrm{PO}_{2}$ coincided with an improved ROS defense system, as compared to swimbladder tissue not used for aerial respiration. In consequence, hypoxic or hyperoxic conditions did not have a strong influence on the capacity of the ROS defense system. In the traira, which uses the swimbladder as a buoyancy organ and not for breathing air, swimbladder $\mathrm{PO}_{2}$ values remained constant, irrespective of environmental $\mathrm{PO}_{2}$. Changing environmental $\mathrm{PO}_{2}$ values, however, caused a much stronger response in the ROS defense system than observed in jeju. This indicated that changes in environmental $\mathrm{PO}_{2}$ may influence the ROS defense system not only in tissues immediately exposed to the varying $\mathrm{PO}_{2}$ but also in organs not directly confronted with the modified $\mathrm{PO}_{2}$.

Acknowledgements Open access funding provided by University of Innsbruck and Medical University of Innsbruck. Financial support by INCT ADAPTA-CNPq/FAPEAM, Science without Borders (Brazil), and NSERC Discovery (Canada) is gratefully acknowledged. ALV is a recipient of a research fellowship from Brazilian CNPq. EJ was supported UBC Go Global. The authors would like to thank Gilda Pelster for support in performing the biochemical assays, and Drs Bill Milsom and Colin Brauner, UBC, for the loan of the Presens system. 
Open Access This article is distributed under the terms of the Creative Commons Attribution 4.0 International License (http://creativecommons.org/licenses/by/4.0/), which permits unrestricted use, distribution, and reproduction in any medium, provided you give appropriate credit to the original author(s) and the source, provide a link to the Creative Commons license, and indicate if changes were made.

\section{References}

Bradford MM (1976) A rapid and sensitive method for the quantitation of microgram quantities of protein utilizing the principle of protein- dye binding. Anal Biochem 72:248-54

Diaz RJ, Breitburg DL (2009) The hypoxic environment. In: Richards JG, Farrell AP, Brauner CJ (eds) Hypoxia. Elsevier, Amsterdam, pp 1-23

Farrell AP, Randall DJ (1978) Air-breathing mechanics in two Amazonian teleosts, Arapaima gigas and Hoplerythrinus unitaeniatus. Can J Zool 56:939-945

Gilmour KM, Perry SF (1994) The effects of hypoxia, hyperoxia or hypercapnia on the acid-base disequilibrium in the arterial blood of rainbow trout. J Exp Biol 192:269-284

Glass ML, Rantin FT (2009) Gas exchange and control of respiration in air-breathing Teleost fish. In: Glass ML, Wood SC (eds) Cardiorespiratory control in vertebrates-evolutionary and evolutionary aspects. Springer, Heidelberg, pp 99-120

Hermes-Lima M (2004) Oxygen in biology and biochemistry: the role of free radicals. In: Storey KB (ed) Functional metabolism: regulation and adaptation. Wiley-Liss, Hoboken, pp 319-368

Hermes-Lima M, Storey JM, Storey KB (1998) Antioxidant defenses and metabolic depression: the hypothesis of preparation for oxidative stress in land snails. Comp Biochem Physiol Part B 120:437-448

Juca-Chagas R (2004) Air breathing of the neotropical fishes Lepidosiren paradoxa, Hoplerythrinus unitaeniatus and Hoplosternum littorale during aquatic hypoxia. Comp Biochem Physiol A Mol Integr Physiol 139(1):49-53

Kramer DL (1978) Ventilation of the respiratory gas bladder in Hoplerythrinus unitaeniatus (Pisces, Characoidei, Erythrinidae). Can J Zool 56:931-938

Kristensen T, Rosseland BO, Kiessling A, Djordevic B, Massabau JC (2010) Lack of arterial PO2 downregulation in Atlantic salmon (Salmo salar L.) during long-term normoxia and hyperoxia. Fish Physiol Biochem 36(4):1087-1095

Leveelahti L, Rytkönen K, Renshaw G, Nikinmaa M (2014) Revisiting redox-active antioxidant defenses in response to hypoxic challenge in both hypoxia-tolerant and hypoxia-sensitive fish species. Fish Physiol Biochem 40(1):183-191

Lopes JM, de Lima Boijink C, Florindo LH, Leite CAC, Kalinin AL, Milsom WK, Rantin FT (2010) Hypoxic cardiorespiratory reflexes in the facultative air-breathing fish jeju (Hoplerythrinus unitaeniatus): role of branchial $\mathrm{O}_{2}$ chemoreceptors. J Comp Physiol B 180(6):797-811

Lushchak VI (2011) Environmentally induced oxidative stress in aquatic animals. Aquatic Toxicol 101(1):13-30

Lushchak VI, Bagnyukova TV (2006) Effects of different environmental oxygen levels on free radical processes in fish. Comp Biochem Physiol B Biochem Mol Biol 144(3):283-289

Lushchak VI, Bagnyukova TV (2007) Hypoxia induces oxidative stress in tissues of a goby, the rotan Perccottus glenii. Comp Biochem Physiol B Biochem Mol Biol 148(4):390-397

Lushchak VI, Lushchak LP, Mota AA, Hermes-Lima M (2001) Oxidative stress and antioxidant defenses in goldfish Carassius auratus during anoxia and reoxygenation. Am J Physiol Regul Integr Comp Physiol 280(1):R100-R107

Lushchak VI, Bagnyukova TV, Husak VV, Luzhna LI, Lushchak OV, Storey KB (2005a) Hyperoxia results in transient oxidative stress and an adaptive response by antioxidant enzymes in goldfish tissues. Int J Biochem Cell Biol 37(8):1670-1680

Lushchak VI, Bagnyukova TV, Lushchak OV, Storey JM, Storey KB (2005b) Hypoxia and recovery perturb free radical processes and antioxidant potential in common carp (Cyprinus carpio) tissues. Int J Biochem Cell Biol 37(6):1319-1330

Lygren B, Hamre K, Waagbo R (2000) Effect of induced hyperoxia on the antioxidant status of Atlantic salmon Salmo salar L. fed three different levels of dietary vitamin E. Aquacult Res 31(4):401-407

McCord JM, Fridovich I (1969) Superoxide dismutase. an enzymic function for erythrocuprein (Hemocuprein)*. J Biol Chem 244:49-55

Milsom WK (2012) New insights into gill chemoreception: receptor distribution and roles in water and air breathing fish. Respir Physiol Neurobiol 184(3):326-339

Morris SM, Albright JT (1984) Catalase, glutathione peroxidase, and superoxide dismutase in the rete mirabile and gas gland epithelium of six species of marine fishes. J Exp Zool 232:29-39

Muusze B, Marcon J, Van den Thillart G, Almeida-Val V (1998) Hypoxia tolerance of Amazon fish: respirometry and energy metabolism of the cichlid Astronotus ocellatus. Comp Biochem Physiol Part A 120:151-156

Oehlers LP, Perez AN, Walter RB (2007) Detection of hypoxia-related proteins in medaka (Oryzias latipes) brain tissue by difference gel electrophoresis and de novo sequencing of 4-sulfophenyl isothiocyanate-derivatized peptides by matrix-assisted laser desorption/ionization time-of-flight mass spectrometry. Comp Biochem Physiol Part C Toxicol Pharmacol 145(1):120-133

Oliveira RD, Lopes JM, Sanches JR, Kalinin AL, Glass ML, Rantin FT (2004) Cardiorespiratory responses of the facultative air-breathing fish jeju, Hoplerythrinus unitaeniatus (Teleostei, Erythrinidae), exposed to graded ambient hypoxia. Comp Biochem Physiol Part A Mol Integr Physiol 139(4):479-485

Paital B (2013) Antioxidant and oxidative stress parameters in brain of Heteropneustes fossilis under air exposure condition; role of mitochondrial electron transport chain. Ecotoxicol Environ Saf 95(0):69-77

Paital B (2014) Modulation of redox regulatory molecules and electron transport chain activity in muscle of air breathing fish Heteropneustes fossilis under air exposure stress. J Comp Physiol B 184(1):65-76

Pelster B (2015) Swimbladder function and the spawning migration of the European eel Anguilla anguilla. Front Physiol 5:486

Pelster B, Giacomin M, Wood CM, Val AL (2016) Improved ROS defense in the swimbladder of a facultative air-breathing erythrinid fish, jeju, compared to a non-air-breathing close relative, traira. J Comp Physiol B 186(5):615-624

Perry SF, Reid SG, Gilmour KM, Boijink CL, Lopes JM, Milsom WK, Rantin FT (2004) A comparison of adrenergic stress responses in three tropical teleosts exposed to acute hypoxia. Am J Physiol Regul Integr Comp Physiol 287(1):R188-R197

Piiper J (1965) Physiological equilibria of gas cavities in the body. In: Fenn WO, Rahn H (eds) Handbook of physiology, respiration, 2 edn. American Physiological Society, Bethesda, pp 1205-1218

Piiper J, Canfield RE, Rahn H (1962) Absorption of various inert gases from subcutaneous gas pockets in rats. J Appl Physiol 17:268-274

Randall DJ, Burggren WW, Farrell AP, Haswell MS (1981) The evolution of air-breathing in vertebrates. Cambridge University Press, Cambridge

Rantin FT, Kalinin AL, Glass ML, Fernandes MN (1992) Respiratory responses to hypoxia in relation to mode of life of two erythrinid 
species (Hoplias malabaricus and Hoplias lacerdae). J Fish Biol 41(5):805-812

Ritola O, Livingstone DR, Peters LD, Lindström-Seppä P (2002a) Antioxidant processes are affected in juvenile rainbow trout (Oncorhynchus mykiss) exposed to ozone and oxygen-supersaturated water. Aquaculture 210:1-19

Ritola O, Peters LD, Livingstone DR, Lindström-Seppä P (2002b) Effects of in vitro exposure to ozone and/or hyperoxia on superoxide dismutase, catalase, glutathione and lipid peroxidation in red blood cells and plasma of rainbow trout, Oncorhynchus mykiss (Walbaum). Aquacult Res 33(3):165-175

Schneebauer G, Hanel R, Pelster B (2016) Anguillicola crassus impairs the silvering-related enhancements of the ROS defense capacity in swimbladder tissue of the European eel (Anguilla anguilla). $\mathrm{J}$ Comp Physiol B 186(7):867-877

Stevens ED, Holeton GF (1978) The partitioning of oxygen uptake from air and from water by erythrinids. Can J Zool 56(4):965-969

Storey KB (1996) Oxidative stress: animal adaptations in nature. Braz J Med Biol Res 29:1715-1733

Tripathi RK, Mohindra V, Singh A, Kumar R, Mishra RM, Jena JK (2013) Physiological responses to acute experimental hypoxia in the air-breathing Indian catfish, Clarias batrachus (Linnaeus, 1758). J Bioscience 38:373-383
Val AL, Almeida-Val VMF (1995) Fishes of the Amazon and their environment. Springer, Berlin

Vig E, Nemcsok J (1989) The effects of hypoxia and paraquat on the superoxide dismutase activity in different organs of carp, Cyprinus carpio L. J Fish Biol 35(1):23-25

Welker AF, Moreira DC, Campos EG, Hermes-Lima M (2013) Role of redox metabolism for adaptation of aquatic animals to drastic changes in oxygen availability. Comp Biochem Physiol A Mol Integr Physiol 165(4):384-404

Wilhelm Filho DW (1996) Fish antioxidant defenses-a comparative approach. Brazilian J Med Biol Res 29:1735-1742

Wilhelm Filho D, Torres MA, Zaniboni-Filho E, Pedrosa RC (2005) Effect of different oxygen tensions on weight gain, feed conversion, and antioxidant status in piapara., Leporinus elongatus (Valenciennes, 1847). Aquaculture 244:349-357

Wood CM, Pelster B, Giacomin M, Sadauskas-Henrique H, AlmeidaVal VM, Val AL (2016) The transition from water-breathing to air-breathing is associated with a shift in ion uptake from gills to gut: a study of two closely related erythrinid teleosts, Hoplerythrinus unitaeniatus and Hoplias malabaricus. J Comp Physiol B 186(4):431-445

Zachar PC, Jonz MG (2012) Neuroepithelial cells of the gill and their role in oxygen sensing. Respir Physiol Neurobiol 184(3):301-308 